\title{
Germline mutation landscape of multiple endocrine neoplasia type 1 using full gene next-generation sequencing
}

\author{
Rafael A Carvalho', Betsaida Urtremari', Alexander A L Jorge ${ }^{1}$, Lucas S Santana', Elisangela P S Quedas', \\ Tomoko Sekiya1, Viviane C Longuini', Fabio L M Montenegro², Antonio M Lerario³, Sergio P A Toledo',4, \\ Stephen J Marx ${ }^{1,5}$, Rodrigo A Toledo ${ }^{6}$ and Delmar M Lourenço Jr ${ }^{1,7}$
}

'Unidade de Endocrinologia Genetica UEG, Laboratorio de Endocrinologia Celular e Molecular LIM-25, Disciplina de Endocrinologia, 2Unidade de Paratireoide, Laboratorio de Cirurgia Vascular e da Cabeça e Pescoço LIM-28, Disciplina de Cirurgia de Cabeça e Pescoço, Hospital das Clinicas HCFMUSP, Faculdade de Medicina, Universidade de Sao Paulo, Sao Paulo, Sao Paulo, Brazil, ${ }^{3}$ Division of Metabolism, Department of Internal Medicine, Endocrinology and Diabetes, University of Michigan, Ann Arbor, Michigan, USA, ${ }^{4}$ Endocrinology Division, Federal University of Sao Paulo (UNIFESP), São Paulo, Brazil, ${ }^{5}$ Endocrinology, Eunice Kennedy Shriver National Institute of Child Health and Human Development (NICHD), Bethesda, Maryland, USA, ${ }^{6}$ Vall d'Hebron Institute of Oncology, Barcelona, Spain, and ${ }^{7}$ Disciplina de Endocrinologia, Instituto do Cancer do Estado de Sao Paulo ICESP, Faculdade de Medicina, Universidade de Sao Paulo, Sao Paulo, Sao Paulo, Brazil

Correspondence should be addressed to D M Lourenço Email delmarmuniz@hotmail.com

\begin{abstract}
Background: Loss-of-function germline MEN1 gene mutations account for $75-95 \%$ of patients with multiple endocrine neoplasia type 1 (MEN1). It has been postulated that mutations in non-coding regions of MEN1 might occur in some of the remaining patients; however, this hypothesis has not yet been fully investigated.

Objective: To sequence for the entire MEN1 including promoter, exons and introns in a large MEN1 cohort and determine the mutation profile.

Methods and patients: A target next-generation sequencing (tNGS) assay comprising $7.2 \mathrm{~kb}$ of the full MEN1 was developed to investigate germline mutations in 76 unrelated MEN1 probands (49 familial, 27 sporadic). tNGS results were validated by Sanger sequencing (SS), and multiplex ligation-dependent probe amplification (MLPA) assay was applied when no mutations were identifiable by both tNGS and SS.

Results: Germline MEN1 variants were verified in coding region and splicing sites of $57 / 76$ patients $(74 \%)$ by both tNGS and SS (100\% reproducibility). Thirty-eight different pathogenic or likely pathogenic variants were identified, including 13 new and six recurrent variants. Three large deletions were detected by MLPA only. No mutation was detected in 16 patients. In untranslated, regulatory or in deep intronic MEN1 regions of the 76 MEN1 cases, no point or short indel pathogenic variants were found in untranslated, although 33 benign/likely benign and three new VUS variants were detected.

Conclusions: Our study documents that point or short indel mutations in non-coding regions of MEN1 are very rare events. Also, tNGS proved to be a highly effective technology for routine genetic MEN1 testing.

\section{Introduction}

Multiple endocrine neoplasia type 1 (MEN1, OMIM \#131100) is a rare and complex inherited cancer syndrome transmitted with autosomal dominant inheritance that predisposes individuals to the development of more than 20 endocrine and non-endocrine tumors. Despite variable frequencies in different series, parathyroid tumors 
(82-100\%) leading to hyperparathyroidism (HPT), in addition to pituitary (PIT) (19-65\%) and pancreatoduodenal endocrine tumors (PET) (41-100\%), are the most prevalent endocrine tumors in MEN1. It is estimated that $50 \%$ of patients carrying germline mutations in the MEN1 tumor suppressor gene will develop at least one MEN1-related tumor up to 20 years of age and almost all cases will present clinical disease at 50 years. Absence of correlation between genotype and phenotype as well as a wide intra-familial clinical variability have been reported in MEN1cases $(1,2,3,4,5,6,7,8,9,10,11)$. Presently, the major causes of death are malignant PETs and thymic carcinoid tumors and patients have a shorter life expectancy $(12,13)$. Compared to familial MEN1, sporadic cases are usually older at the time of diagnosis, live longer and exhibit no more than two MEN1-related tumors (14).

MEN1 (OMIM \# 613733) is a 10-exon gene with $1830 \mathrm{bp}$ in the coding region that encodes the 610 amino acid protein menin, which interacts with at least 12 proteins and regulates transcription, genome stability, cell division and proliferation $(5,6,8)$. Germline heterozygous MEN1 mutations are responsible for 75-95\% of MEN1 phenotypes $(5,6,8,15,16,17,18,19)$. Importantly, up to $5-25 \%$ of patients may not harbor MEN1 mutations in the coding region, $10 \%$ of cases are due to de novo MEN1 mutations and 5-10\% are phenocopies (5). Rarely (3.5\%), MEN1-negative carriers with MEN1-like phenotypes may harbor germline mutations in the $C D K N 2 B / p 15$, CDKN2C/p18 CDKN1A/p21, CDKN1B/p27 and AIP genes $(20,21,22)$

Most MEN1 mutations are frameshift and nonsense (56-64\%), which predict truncated menin-protein missing at least one out of the three nuclear localization signals located at the C-terminal segment $(19,23)$. Thus, menin becomes unable to suppress transcription factors, leading to predisposition for tumor formation. Missense variants represent one quarter of the different mutations types, whereas splice-site and in-frame indels are also represented and frequently interfere in menin-protein interactions $(5$, $8,19,23)$. In turn, gross deletions correspond to $2.5 \%$ of the different mutation types, occur in 1\% of MEN1 cases and are usually investigated using assays as multiplex ligation-dependent probe amplification (MLPA) $(19,23)$.

The identification of MEN1 germline mutation is highly useful because it confirms the clinical diagnosis of the MEN1 index case, defines the carrier and non-carrier status of at-risk family members, rules out non-carriers from long-term periodic follow-up and allows prenatal and preimplantation genetic diagnosis. Therefore, MEN1 testing substantially optimizes genetic counseling, surveillance and therapeutic strategies $(1,2,3,4,5,6,8$, $9,10,11,12,24)$. Early genetic diagnosis promotes early clinical diagnosis and treatment of MEN1-related tumors that has a consistent positive impact on morbidity, quality of life and survival rate $(1,2,3,4,5,6,7,8,13,24)$. In contrast, detrimental consequences of delayed diagnosis should not be underestimated (25).

Current MEN1 guidelines recommend MEN1 mutation testing for cases far beyond the classical MEN1 phenotype and symptomatic or asymptomatic first-degree relatives $(1,5)$. Genetic testing should be also offered for several sporadic cases with MEN1-related tumors, such as multiglandular parathyroid disease, gastrinoma and multiple PET at any age; parathyroid hyperplasia (<40 years); recurrent HPT; several atypical MEN1-related phenotypes (5) and, more recently, PIT macroadenoma identified at a young age, adding a substantial number of cases to be genetically tested (26). This goal should be pursued as genetic diagnosis provides an opportunity for earlier treatment, avoiding comorbidities as those associated with HPT, PIT macroadenomas or PETs $(3,4,5$, $6,7,8,9,10,11,12,13,14,24,25,26,27)$.

MEN1 testing has been usually performed using both Sanger sequencing (SS) and MLPA assays (5, 8, 9, 13, 23, $28,29,30)$. Although genetic testing should be ideally performed in literally all cases fulfilling current criteria, SS technology has limitations to achieve this purpose. Thus, the MEN1 gene is relatively large and lacks mutational hotspots making SS a burdensome, time-consuming, laborious and expensive technique. Moreover, in MEN1 patients with no mutation in the coding region of the MEN1 gene, it has been postulated the existence of MEN1 mutations in introns far from intron/exon boundaries, untranslated or regulatory regions $(5,8,10,13,18,19,23$, $28,29,30)$. However, SS may not usually cover such gene regions, preventing systematic studies on this topic $(5,8$, $10,13,18,19,23,28,29,30)$. Therefore, novel, higherthroughput and greater capacity of data generation, robust and affordable strategies as NGS technologies are required $(31,32,33,34)$. NGS is feasible in clinical practice today and different NGS strategies have been adopted for hereditary cancer syndromes, such as WGS, WES and tNGS sequencing $(31,32,33,34)$.

So far, the few available NGS studies evaluating the MEN1 gene have applied WES or WGS approaches, confirming the presence of occasional somatic MEN1 mutations in several sporadic tumors beyond biallelic MEN1 inactivation in parathyroid tissues from MEN1 
patients $(35,36,37,38,39)$. Germline MEN1 mutations were analyzed in three studies using WES, in a large primary hyperparathyroidism family and in five MEN1 cases (38, $39,40)$. Also, a 22 genes tNGS panel including MEN1 was recently applied to investigate somatic mutations in sporadic pancreatic neuroendocrine tumors (41). In addition, an eight-gene tNGS panel was applied to search germline mutations in young patients with pituitary adenoma (42). However, despite tNGS being cheaper and faster than WES and WGS, there is no previous systematic study using this technology as a genetic diagnostic tool in MEN1 syndrome $(8,9,13,43)$. Worthwhile, independent of which NGS technology is used, caution should be exercised to avoid errors and misinterpretations that may carry negative clinical impacts $(44,45)$.

In the present study, we applied tNGS to our MEN1 cases to investigate the full MEN1 gene including coding and non-coding regions, searching for mutations possibly occurring in introns far from intron/exon boundaries and untranslated and regulatory regions. Also, we compared tNGS and SS data to validate the former technology for MEN1 testing in MEN1.

\section{Patients and methods}

\section{Patients}

The study was approved by the Local Ethical Committee (CAPPesq), and written, fully informed consent was given by all patients or their parents. Both tNGS and SS assays were conducted in peripheral blood leukocyte DNA samples obtained from 76 apparently unrelated index cases with a clinical diagnosis of MEN1. Thirtyone affected men (mean age, $40 \pm 15$ years; 7-69 years) and 45 women (mean age, $41 \pm 11$ years; $19-67$ years) were enrolled, and the overall mean age at diagnosis was $40 \pm 13$ years ( $7-69$ years)

The clinical diagnosis of MEN1 was defined as previously established (1, 5, 27). Familial MEN1 was characterized by the combined presence of a MEN1 index case and at least one first-degree family member with one or more main MEN1-related tumors (HPT, PET, PIT). Sporadic MEN1 was defined as the presence of an isolated case with the clinical diagnosis of MEN1 and unsatisfactory/unknown or negative MEN1 familial history. Probands were considered apparently unrelated when they clearly stated no to be related to any other patient enrolled in this study.

\section{Classification of variants}

MEN1 gene variants were classified following criteria of the American College of Medical Genetics and Genomics (ACMG), which characterize variants as benign, likely benign, variants of uncertain significance (VUS), likely pathogenic and pathogenic based on clinical, computational, segregation and population data $(46,47)$. In addition, to reinforce segregation data, the segregation equation $N=(1 / 2)^{m}$, as defined by Jarvik (48), was supported, where $N$ means the probability of the observed variant occur by chance (no pathogenic) and $m$ defines the number of meiosis of the variant that is informative for segregation, excluding the index case. The criteria to pathogenicity $(P)$ are dependent on segregation data coming from either one family (a) or two or more analyzed families (b). For these groups, different cutoffs define a grading of evidence levels of pathogenicity: supporting evidence (a, $P \leq 1 / 8 ; \mathrm{b}, \quad P \leq 1 / 4)$, moderate evidence (a, $P \leq 1 / 16 ; \mathrm{b}, P \leq 1 / 8)$ and strong evidence (a, $P \leq 1 / 32$; b, $P \leq 1 / 16)(48)$.

In MEN1 patients presenting germline mutations, the vast majority $(>96 \%)$ of cases will harbor a MEN1 mutation $(1,2,3,4,5,6,7,8,13,14,15,16,17,18,19$, $20,21,22,23,24,43)$. Thus, we determined the MEN1 as a target in NGS and SS.

\section{Sanger sequencing}

In our tertiary academic hospital, we have been routinely offering DNA genetic diagnosis for MEN1 patients since 2004 using SS and, more recently, multiplex ligationdependent probe amplification (MLPA) (3, 4, 18, 49, 50 , 51). Beyond MEN1, other genes as $C D K N 2 B / p 15$, CDKN2C/p18 CDKN1A/p21, CDKN1B/p27 and AIP have been analyzed in our patients with MEN1-like conditions, sporadic MEN1-related tumors and familial acromegaly $(52,53,54)$.

For SS, amplicons were obtained through PCR of the complete coding DNA sequence (CDS) $( \pm 50$ bp upstream /downstream) using eight primer pairs. Amplicons were purified with Illustra ExoProStar 1-step (GE Healthcare) and sequenced using Big Dye terminator v3.1 (Thermo Fisher). Capillary electrophoresis (CE) was conducted in an ABI 3130xl automatic sequencer (Thermo Fisher). After data acquisition, AB1 files were analyzed using CodonCode Aligner version 5.0 (CodonCode, MA, USA) using as references the MEN1 gene sequence (ENSG00000133895 or NG_008929.1) and transcript 
MEN1-001 (ENST00000312049 or NM_130799.2), as this transcript codes for the main functional isoform of MEN1.

\section{NGS libraries and sequencing}

For NGS, the targeted sequence was amplified by long-

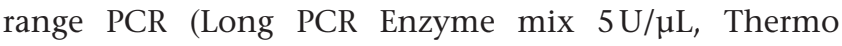
Fisher) using one primer pair to amplify the entire MEN1 gene (coding regions, introns, untranslated and regulatory regions). The primer sequences were forward, TAACAGACACTGATACCCAGCTAAAGC and reverse, GGGATACGAAGGAGAGGAAACTAGG (both 5'-3'). The amplicon size obtained was 7239 bp (GRCh37/hg19 chr11:64571249-64578487), following the manufacturer's instructions.

Supplementary data (see section on supplementary data given at the end of this article) shows detailed data on cycling conditions and quantification of amplicons, preparation of libraries, sequencing using MiSeq Illumina platform and softwares applied to data processing, generation of pipelines to provide running quality metrics and inspection of reads and comparative analysis of tNGS with SS. Also, The impact and effects of variants were analyzed using seven different databases: dbSNP (http://www.ncbi.nlm.nih.gov/SNP/), Leiden Open Variation Database (LOVD) (http://www.lovd.nl/3.0 /home), Ensembl (http://www.ensembl.org/index.html), Catalogue of Somatic Mutations in Cancer (COSMIC) (http://cancer.sanger.ac.uk/cosmic), the Human Gene Mutation Database (HGMD) (http://www.hgmd.cf.ac.uk /ac/index.php), GnomAD (http://gnomad.broadinstitute. org) and ABraOM (http://abraom.ib.usp.br/). In parallel, predictive algorithms used for in silico analysis and clinical databases consulted are found in Supplementary data.

We preliminarily applied a five-gene panel to a strict subset of nine available MEN1-negative carriers, following the same protocol previously defined and optimized for the MEN1 tNGS assay, aiming to investigate germline mutations in $C D K N 2 B / p 15, C D K N 2 C / p 18 C D K N 1 A / p 21$, $C D K N 1 B / p 27$ and AIP genes. As for the MEN1 tNGS assay, the panel covered the full open reading frame of the five genes using specific long-range PCR (Supplementary data).

\section{Multiplex ligation-dependent probe amplification (MLPA)}

Amplicon-based tNGS and also SS are not able to detect gross deletions. Thus, MLPA was provided to MEN1-negative carriers. For this analysis, we applied the MLPA kit P244, targeting MEN1, AIP and CDKN1B genes.
MLPA probes covered each one of the ten exons of the MEN1 gene including the upstream region. DNA fragment analysis was performed in the same ABI 3130xl CE device (Thermo Fisher) using ROX 500 (Thermo Fisher) as a DNA ladder. Running and injections parameters were used according to the manufacturer's instructions. After DNA fragment electrophoresis, FSA files were analyzed with MRC-Holland's own software, Coffalyser (MRC-Holland, Amsterdam, The Netherlands). The gross deletions identified by MLPA were considered as such only if two consecutives ligation probes were involved. Additionally, sequences obtained by NGS/SS excluded the presence of SNVs on probe ligation sites as they may generate false positive results by MLPA. Also, hemizygous was reinforced by absence of heterozygous SNVs and lower average read depth observed in NGS sequences in deleted regions detected by MLPA.

\section{Statistical analysis}

Statistical analysis was performed using IBM-SPSS software for Windows, version 20.0. Categorical data were described as number of tumors, presence/absence of germline mutation or presence/absence of familial history and association between these characteristics was verified using the chi-squared test. Data with a normal distribution as age at the time of diagnosis had their values expressed as means \pm standard deviation and comparisons between these categories were provided using Student's t-test. As both tNGS and SS assays were performed using DNA from the same blood sample, the percentage agreement statistic and Cohen's kappa test were applied to verify the reliability of tNGS compared to the gold standard SS. A $P$ value $<0.05$ was considered statistically significant.

\section{Results}

\section{Clinical features}

The prevalence of main MEN1-related tumors in the 76 MEN1 patients was, respectively: HPT, 99\% (75/76); PET, 86\% (65/76) and; PIT, 78\% (59/76). Most patients (47/76; $62 \%)$ presented all three main MEN1-related tumors. The remaining 29 patients $(29 / 76 ; 38 \%)$ with two main MEN1-related tumors presented the following tumor associations: HPT/PET (17/76; 22\%), HPT/PIT (11/76; 15\%) and PET/PIT (1/76; 1\%).

Familial MEN1 was clinically diagnosed in 49 patients (49/76, 64\%) whereas the remaining were classified as sporadic cases $(27 / 76 ; 36 \%)$ (Fig. 1). Age at diagnosis of 
the 49 familial cases was $39 \pm 14$ years, while for the 27 sporadic cases it was $41 \pm 14$ years $(P=0.496)$.

\section{Pathogenic MEN1 variants}

Frequency in familial and sporadic MEN1 cases

In our series, heterozygous MEN1 germline variants were documented in 60 out of 76 MEN1 patients (79\%): 57 cases were detected by tNGS and SS (75\%), whereas three others (4\%) harbored large gene deletions documented by MLPA (Fig. 1). Nine cases (9/60; 15\%) with typical MEN1 phenotype (familial or simplex cases) harbored variants classified as likely pathogenic, according

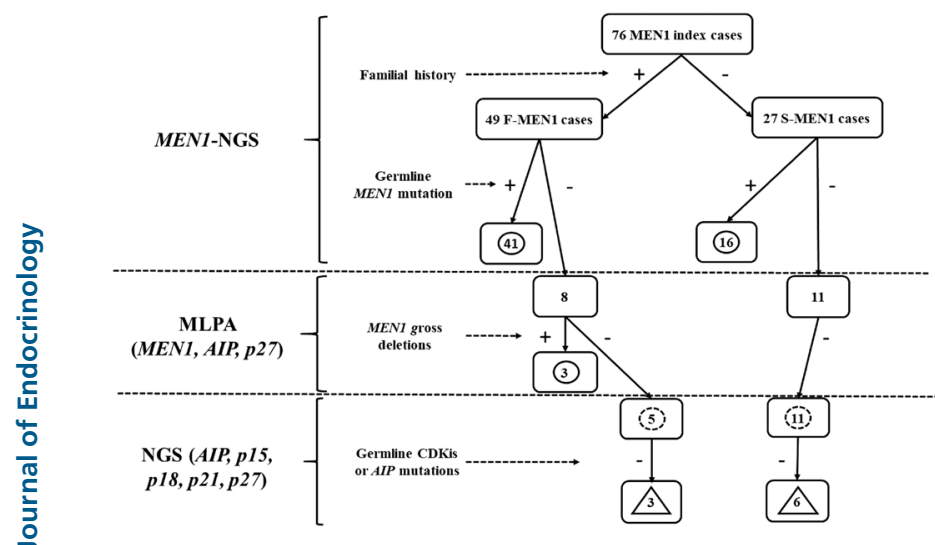

\section{Figure 1}

Flow chart applied to genetic diagnosis of 76 unrelated MEN1 index cases using Targeted Next Generation Sequencing (tNGS) and multiplex ligation-dependent probe amplification (MLPA) assays. MEN1, multiple endocrine neoplasia type 1; F-MEN1, Familial MEN1; S-MEN1, sporadic MEN1; CDKIs, cyclin-dependent kinase inhibitors; NGS assay was based on long-range PCR amplifycation of the full MEN1 open reading frame using MiSeq Illumina platform; MLPA assay was performed to investigate gross deletions in the MEN1, AIP and $C D K N 1 B / p 27$ genes in tNGS/MEN1 mutation-negative patients; nine MEN1-negative cases by tNGS and MEN1/AIP/p27-negative by MLPA were screened to germline mutations by tNGS addressed to CDKIs (CDKN2B/p15, CDKN2Cl p18 CDKN1A/p21, CDKN1B/p27) and AIP genes; circle with full line, positive MEN1-mutation patients identified by MEN1NGS or MEN1-MLPA assays; circle with dashed line, MEN1 mutation-negative patients by NGS or MLPA assays (MEN1, $C D K N 1 B / p 27$ and $A I P$ ); triangle, patients without germline mutation identified in full open reading frames of the MEN1, CDKN2B/p15, CDKN2C/p18 CDKN1A/p21, CDKN1B/p27 and AIP genes by tNGS and with no gross deletions in MEN1, CDKN1B/p27 and AIP by MLPA assay. to criteria from ACMG. Subsequently, after the probability of segregation equation $N=(1 / 2)^{m}$ was applied, three likely pathogenic variants were reclassified as pathogenic. Overall, considering the combined criteria (ACMG and SE), 79\% (60/76) of patients harbored a pathogenic/likely pathogenic MEN1 variant.

In the familial MEN1 subset, 44 cases $(44 / 49 ; 90 \%)$ were mutation carriers: 41 (84\%) were detected by tNGS/SS and three by MLPA assay (6\%). After MEN1 testing, we uncovered 16 newly inherited MEN1 cases out of 27 (59\%) apparently sporadic cases, while the remaining 11 were MEN1-negative carriers (Fig. 1).

In total, 60 MEN1 carriers were documented (75\%), and 16 (five familial, 11 sporadic) were MEN1-negative cases. As expected, the prevalence of germline pathogenic/ likely pathogenic MEN1 variants was higher in familial (44/49; 90\%) than in sporadic $(16 / 27,59 \% ; P=0.002)$ cases. The 16 mutation-negative cases were older than the 60 patients harboring pathogenic/likely pathogenic MEN1 variants ( $38 \pm 14$ years vs $46 \pm 12$ years; $P=0.033$ ). Most MEN1-negative index cases (12/16; 75\%) had no more than two MEN1-related tumors, in comparison with MEN1-positive index cases (20/60, 33\%; $P=0.003)$.

\section{Mutation types}

Overall, 38 different MEN1 variants were identified (Fig. 2). Ten pathogenic and three likely pathogenic MEN1 variants were novel $(13 / 37 ; 35 \%)$, as they were absent from eight available databases (Table 1). All variant types detected by tNGS were also verified by SS and vice versa. Large gene deletions, as expected, were not detected by both methods. Combining results from tNGS/SS and MLPA assays, most variants were frameshift (21/60; 35\%), followed by in splice-site $(14 / 60 ; 23 \%)$, nonsense $(11 / 60$; $18 \%)$, missense $(7 / 60 ; 12 \%)$, in-frame indel variants $(4 / 60$; 7\%) and large deletions (3/60; 5\%) (Fig. 2 and Table 1).

Most (62\%) of the 13 new pathogenic/likely pathogenic variants were predicted to code truncated proteins generated from frameshift deletions/insertions $(6 / 13)$ or nonsense variant (2/13), followed by three in-frame insertion/deletion and one intronic and one missense point mutation.

\section{Analysis of MEN1 variants}

In our cohort, we identified six $(6 / 41 ; 15 \%)$ different missense variants and one of them was new. We again applied the criteria adopted by ACMG $(46,47)$ combined with the probability equation of segregation by chance (48) 


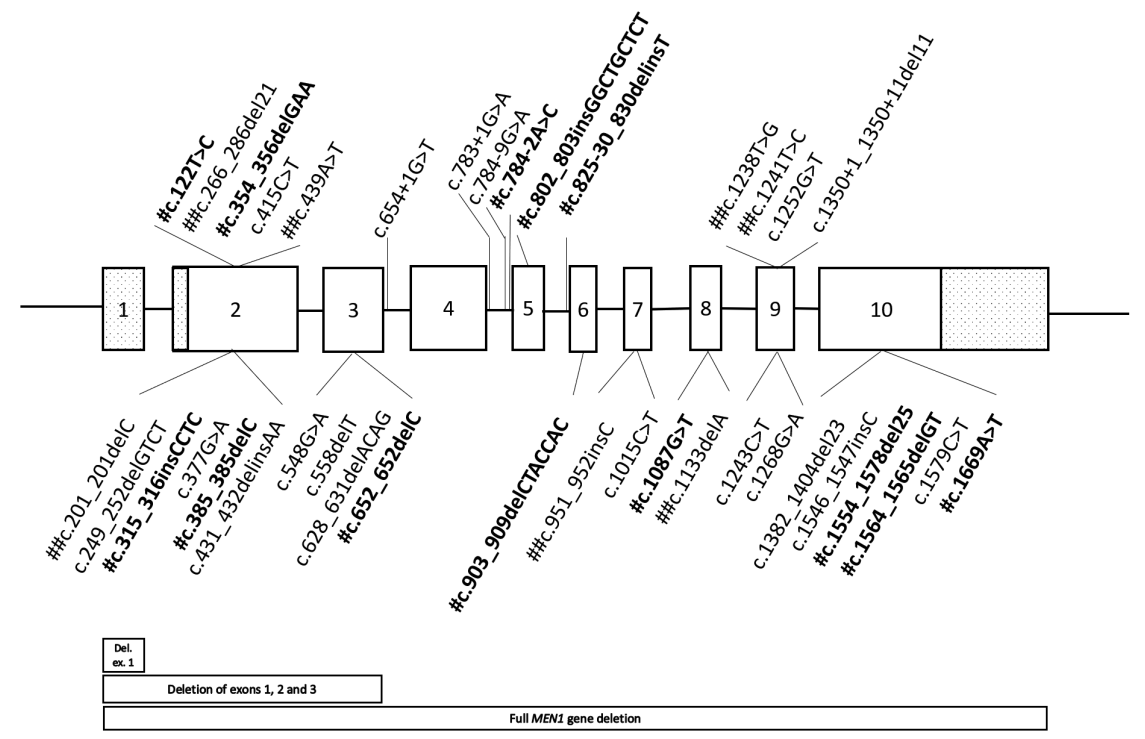

\section{Figure 2}

Mutations were identified in intron-exon frontiers and coding region of the MEN1 gene in 60 out of our cohort of 76 unrelated MEN1 index cases by both tNGS and SS (57 cases), and MLPA assay (3 cases). Truncating mutations (frameshift and nonsense) (NGS and SS) and gross MEN1 deletions (MLPA assay) are represented below diagram while non-truncating (missense and in-frame) and splicing mutations are located above; \#, new mutations reported in the present study; \#\#, mutations previously reported from our cohort $(8,18)$; shadow region corresponds to non-coding regions of the MEN1 gene. to classify pathogenicity of the four new variants (missense and in-frame) and confirm five missense variants and one in-frame previously reported as pathogenic (Table 2).

The new missense variant p.Leu41Pro classified as likely pathologic segregated in four affected at-risk relatives and it was absent in seven other asymptomatic at-risk family members (Table 1 , case 1 ; Table 2). This variant was located at a highly conserved gene region in humans and animals, in the JunD-NM23H1-RPA2SMAD3-interacting domains.

All patients with in-frame variants presented typical features of MEN1 with multiglandular tumor involvement. Three in-frame variants (two new) were classified as likely pathogenic and one as pathogenic.

The new in-frame pathogenic variant c.354_356deGAA (codon 119) found in one de novo case (case 10) was initially classified as likely pathogenic. It was redefined as pathogenic as it occurred in a repetitive region of exon 2 and its mutated sequence was exactly the same generated by 'warm spot' MEN1 mutation c.358_360delAAG described in the subsequent codon $120(16,19)$.

Considering the three patients with likely pathogenic variants, two of them were familial (cases 8 and 56, Tables 1 and 2) and another was a simplex MEN1 case. The latter patient presented a new in-frame variant in exon 5 due to a consecutive duplication of the normal sequence GGCTGCTCT (position 794-802), which resulted in a repetition of the corresponding amino acids (c.802_803insGGCTGCTCT; p.Trp265_Leu267dup) (Table 1, case 20; Table 2). The latter variant was identified in a 43-year-old patient with typical MEN1 phenotype presenting with primary HPT, non-functioning PETs, gastrinoma, bilateral nodular adrenocortical hyperplasia, collagenomas and facial angiofibromas. Familial history showed a brother with urolithiasis and an aunt with breast carcinoma. At-risk family members were invited to come to the hospital, but remained unavailable. Thus, segregation analysis of the variant could not be performed yet (Table 2). This variant was located at NM23H1NMHCIIA-FANCD2-HDAC1-interacting domains.

The p.Leu414Pro missense variant (Table 1, case 28; Table 2), classified as likely pathogenic by ACMG criteria, was absent in six healthy siblings. The index case was aged 28 years and presented a typical MEN1 phenotype characterized by HPT (multiglandular disease), macroprolactinoma, collagenomas and non-functioning adrenal tumor. The latter patient was previously reported by us harboring a pathogenic variant, based on changing of the aliphatic amino acid leucine for the non-aliphatic proline amino acid in a highly conserved region (18).

Overall, analyzing the five different variants previously reported, four of them were initially classified (p.I147F, $p$. Leu413Arg, p.L414P, p.D418Y) as likely pathogenic and p. $\mathrm{H} 139 \mathrm{Y}$ as pathogenic, based on previous in vitro studies (55). In turn, the strength of familial segregation changed the classification of three variants (p.I147F, p.Leu413Arg, p.D418Y) from likely pathogenic to pathogenic (Table 2).

\section{Introns far from exon/intron boundaries, untranslated and regulatory regions}

Notably, no mutation was verified by tNGS in introns far from exon/intron boundaries, untranslated or 


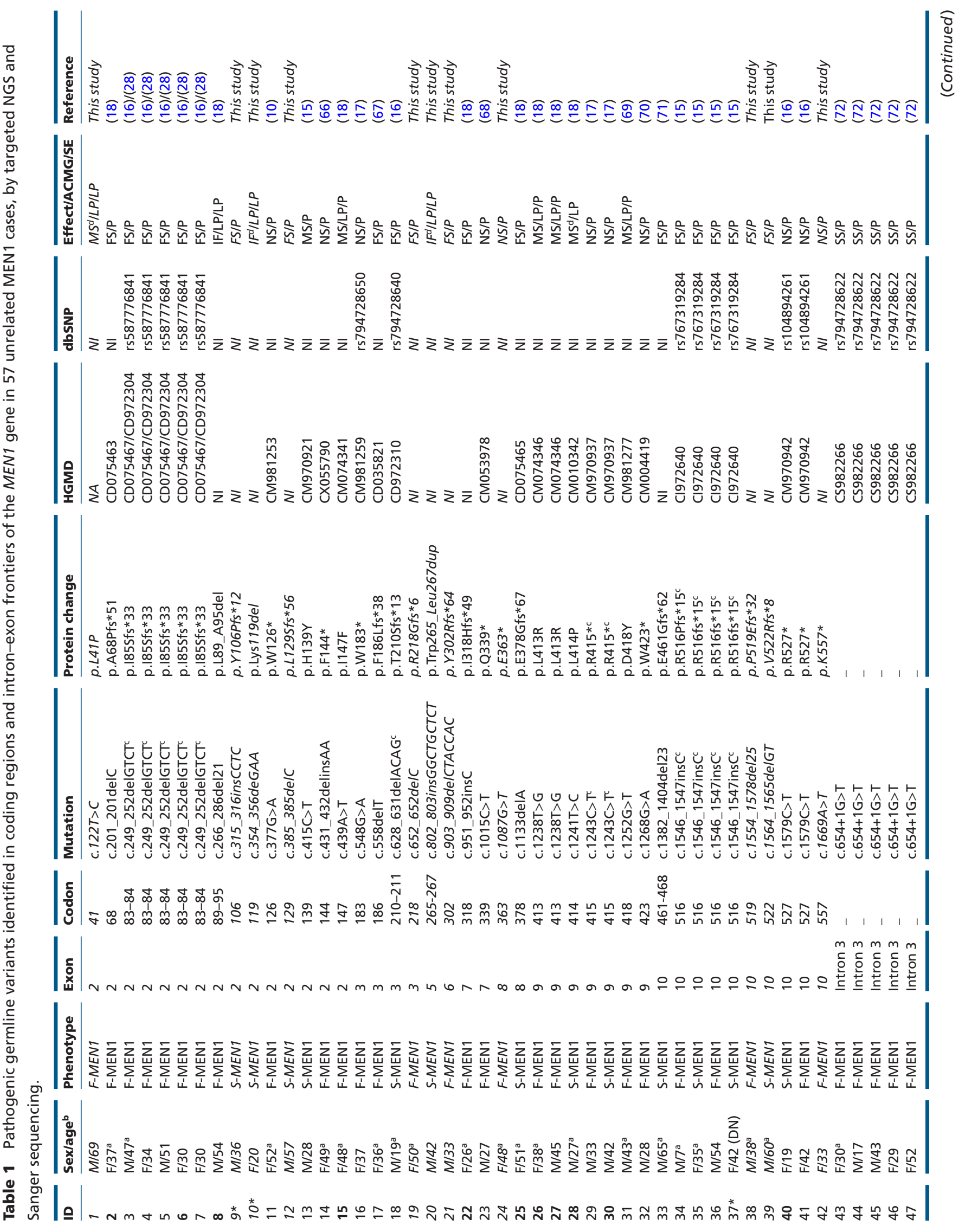



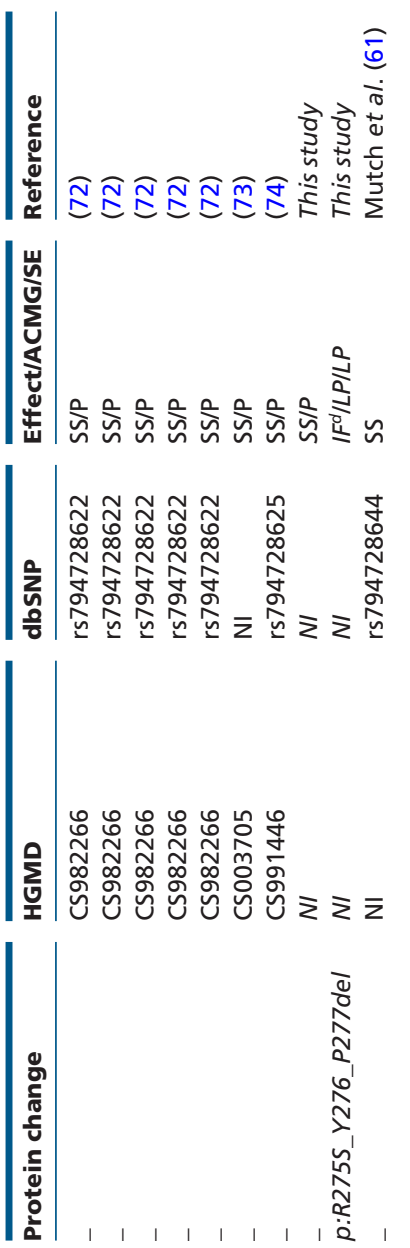

ธٔ

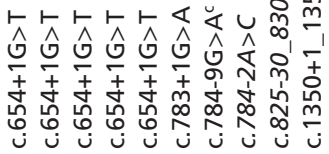

응
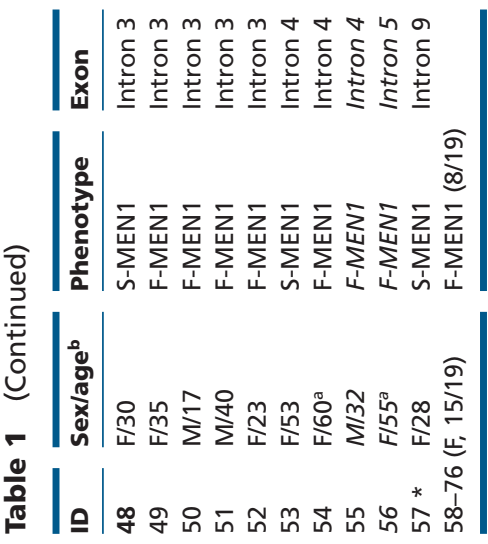
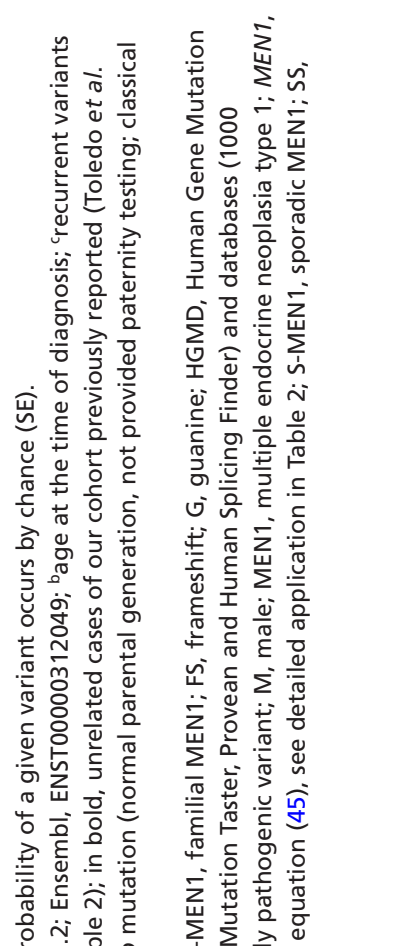

regulatory regions in all 76 MEN1 patients (49 familial and 27 sporadic cases), which evidently include the 16 MEN1-negative carriers. Also, the possibility of a second pathogenic variant was ruled out in 60 MEN1 mutation carriers.

\section{Recurrent mutations and most frequently affected codons}

Germline mutations were spread along the MEN1 gene. In our series, recurrent mutations corresponded to $15 \%$ (6/41) of the different mutation types and were present in 25 apparently unrelated mutation carriers $(25 / 60 ; 42 \%)$ (Table 1). Three of them (c.249_252delGTCT, c.1243C>T, c.1546_1547insC) coincided with 'warm spot' mutations reported by Lemos and Thakker (19) (Table 1). Previous haplotype analysis allowed us to exclude p.L415R as a founding mutation in cases 26 and 27 (18). In case 2, we previously reported the founding mutation c.201_201delC (4) (Table 1). In turn, methodic haplotype analysis was not available in the 22 remaining carriers.

\section{Non-pathogenic variants}

Overall, 36 different benign variants were identified with highly variable frequencies (1.3-96\%) along the full MEN1 gene by tNGS. The polymorphisms were dispersed throughout introns $(22 / 36 ; 61 \%)$, untranslated regions $(7 / 36 ; 19 \%)$ and exons $(7 / 36 ; 19 \%)$. Thus, polymorphisms were four-fold more frequently detected in non-exonic than in exonic regions ( 29 vs 7 ). Four were synonymous and two non-synonymous. Overall, six $(6 / 36 ; 17 \%)$ were characterized as new polymorphic variants, as they were not previously reported in dbSNP, 1000 genomes, COSMIC, 6500 exomes, ABraOM, GnomAD and ExAC (Table 3). Three new variants were highly prevalent (34-52\%): c.445+709_710delTT, c.445+710delT and g.5276_5276delT and were classified as likely benign. They were detected, respectively, in 40, 30 and 26 patients either with or without MEN1 mutations, ranging from 10 to $20 \mathrm{bp}$ and were located in homopolymers. In contrast, the three remaining new polymorphisms had lower frequencies (1.3-4\%), detected in one to three MEN1 patients and only occurred in mutation carriers. They were classified as VUS (Table 3).

The variant c.-23-24T>C (g.1139T>C) in IVS1 seen in our cases was not present in six available international databases, although it was identified in $10.2 \%$ of the Brazilian controls individuals (Table 3). Thus, this variant was classified as benign polymorphism. 


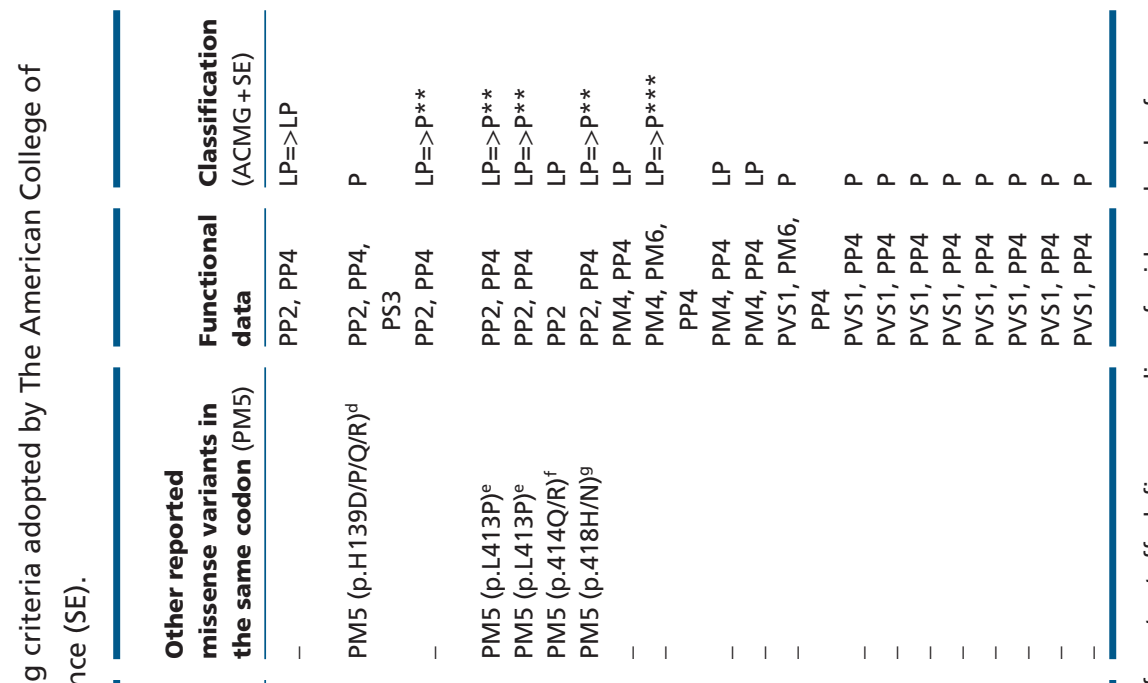

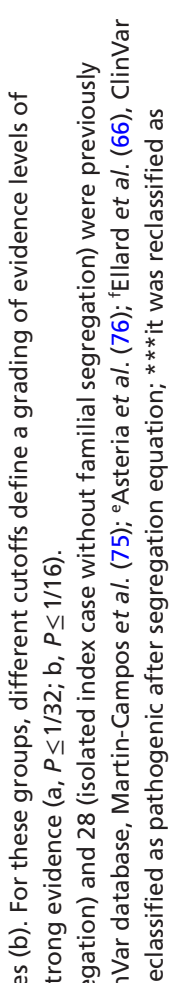

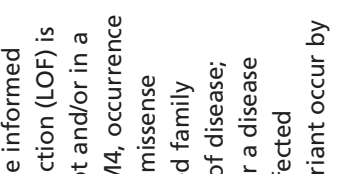

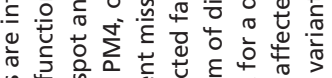

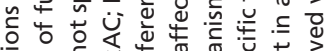

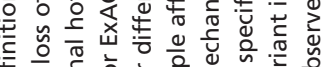

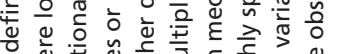

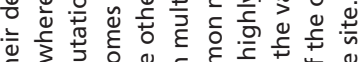

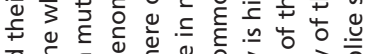

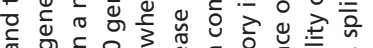

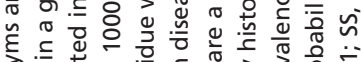

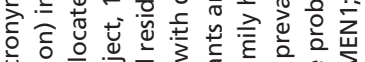

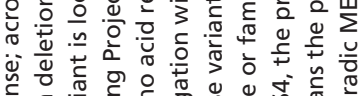

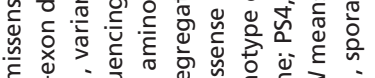

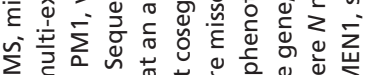

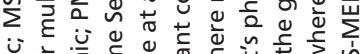

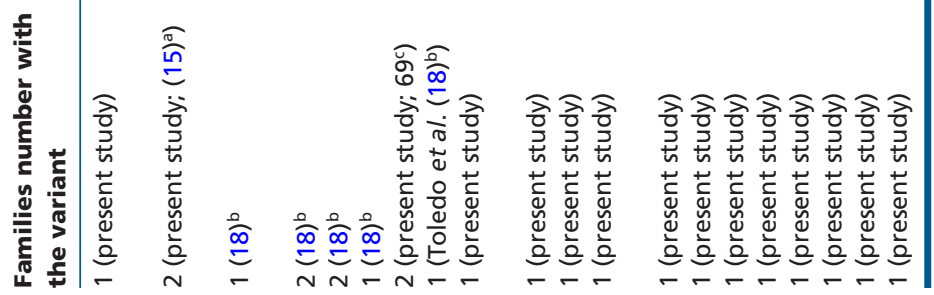

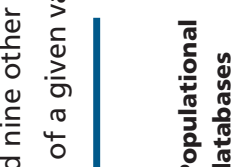

당

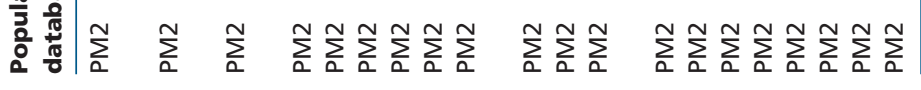

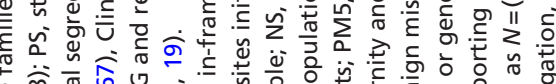

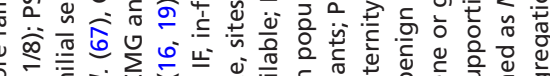

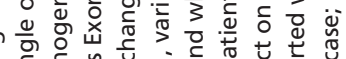

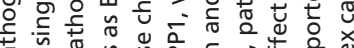

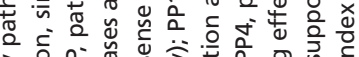

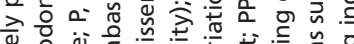

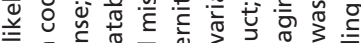

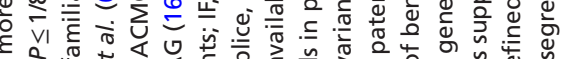



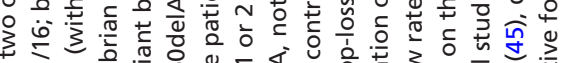

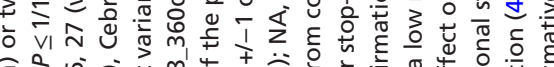

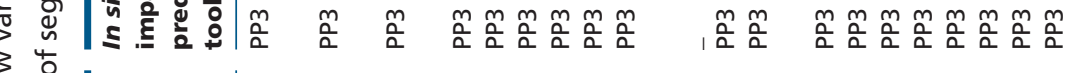

3

苦

$\frac{\sqrt{2}}{\frac{\pi}{6}}$

$\sum$

虫

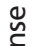

离

है

है

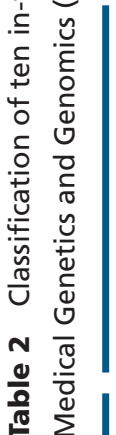

‡

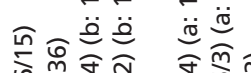

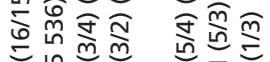

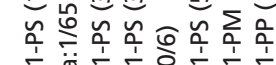

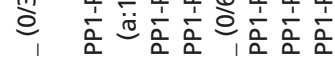

竞

$\sum_{i}^{m}$

$\sum_{i} \sum_{i} \sum_{i} \sum_{i} \sum_{i} \sum_{i} \sum_{j} \sum_{i} \sum_{i} \sum_{i} \sum_{i}^{\underline{u}}$

$\sum_{i} \sum_{i} \sum_{i} \sum_{i}$

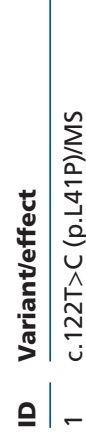

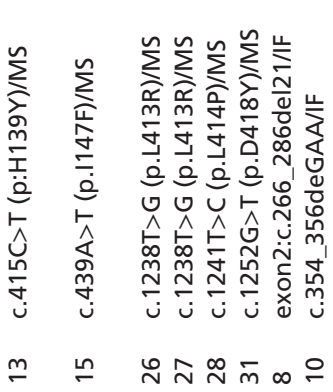

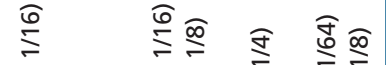

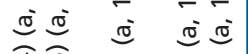

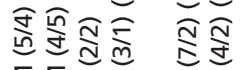

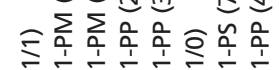

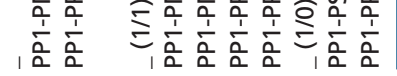

$\sum_{i} \sum_{i} \sum_{i} \sum_{i} \sum_{i} \sum_{i} \sum_{\sum_{i}} \sum_{\sum_{i}} \sum_{\sum_{i}} \sum_{\sum_{i}}$

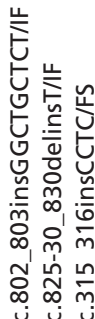

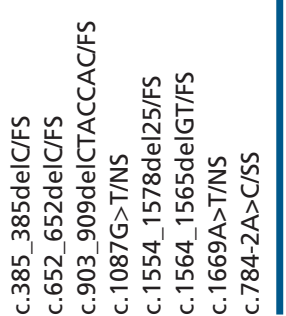

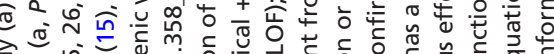

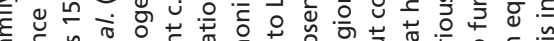

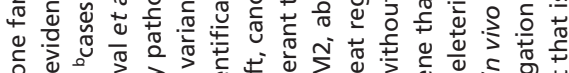

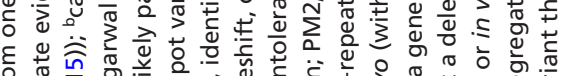

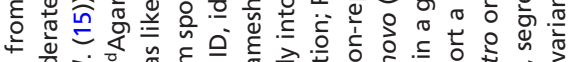

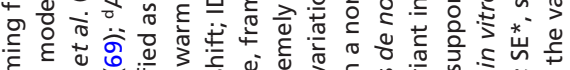

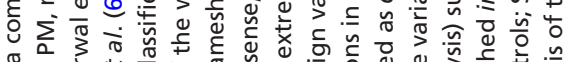

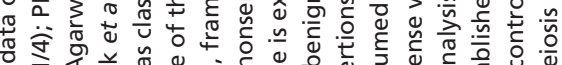

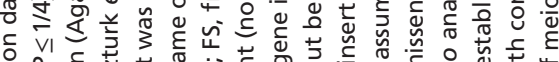

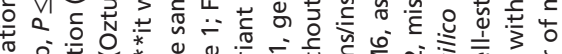

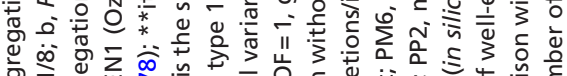

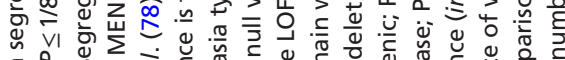

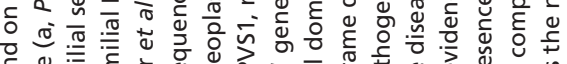

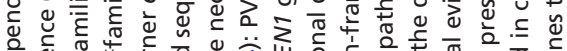

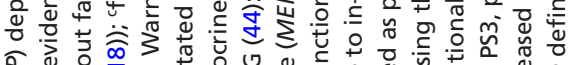

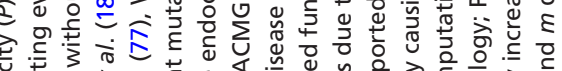

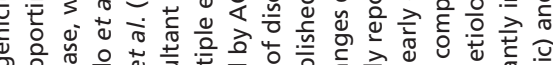

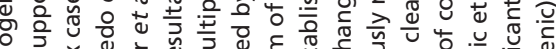

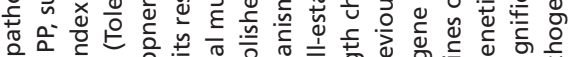

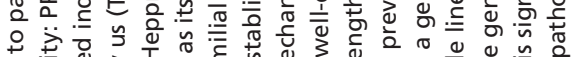

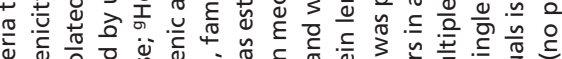

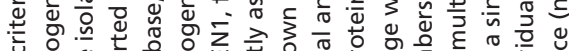

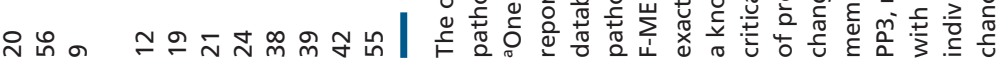


Conversely, only seven polymorphisms were detected by SS in the present cases. Six of them occurred in MEN1-coding region and another in IVS1 region, as the designed primers covered the intron/exon boundary of this region. Comparing data from SS and tNGS, the latter technology yielded a significantly higher polymorphism detection rate (36 vs $7 ; P<0.05$ ).

\section{Multiplex ligation-dependent probe amplification (MLPA)}

MLPA assay was applied for the subset of 19 MEN1-negative patients ( 8 familial and 11 sporadic cases) (Fig. 1). Overall, gross MEN1 deletions were identified in $4 \%(3 / 76)$ of all cases, in 5\% of MEN1-positive patients (5/60), in $6 \%(3 / 49)$ of all familial MEN1 cases and in 37\% (3/8) of MEN1-negative familial MEN1 cases (Fig. 2). Additionally, gross deletions were searched but not identified in the $A I P$ and $C D K N 1 B$ genes by MLPA assay in the 16 truly MEN1-negative cases.

Nine (three familial and six sporadic) available patients for testing out of the 16 MEN1-negative patients were studied. No case harbored mutations in the CDKIs or AIP genes (Fig. 1).

\section{Discussion}

\section{tNGS to detect MEN1 mutations}

Until recently, mutations in coding region and splicing sites of MEN1 have been usually investigated by SS complemented by MLPA for large deletions. However, SS presents limitations in the analysis of the MEN1 gene and besides it may not routinely cover the MEN1 non-coding regions $(5,8,10,13,18,19,23,28,29,30,56)$. In addition, it is highly challenging to perform MEN1 testing in the extended number of cases fulling the current criteria for genetic analysis, using SS (5).

In the present study, we applied tNGS to our 76 cases as it is faster and cheaper than WES and WGS. We compared data from tNGS with SS and both technologies presented identically high accuracy, reproducibility and repeatability with no false positive. Thus, tNGS applied for the genetic diagnosis of MEN1 was validated as a reliable test. A small percentage of false-negative results (5\%) were seen in cases with gross MEN1 deletions, we identified by MLPA. Also, the primer design and reaction optimization of tNGS proved the specificity of the MEN1-targeted longrange PCR methodology, associated with no occurrence of primer cross-reactivity, dimer formation, allelic bias or dropout (34). Additional discussion on the adoption of long-range PCR as enrichment method, criteria to select the NGS platform and cost-effectiveness of tNGS may be found in Supplementary data.

\section{Mutations in introns far from intron/exon boundaries or untranslated or regulatory regions}

Worthwhile, tNGS allowed us to methodically investigate the full MEN1 coding and non-coding regions in all 76 MEN1 patients and no case harbored pathogenic/likely pathogenic variants in introns far from intron/exon boundaries, untranslated or regulatory gene regions. Thus, our present data indicated that point or short indel MEN1 pathogenic/likely pathogenic variants in these gene regions are most probably very rare in MEN1 patients. These findings contrast with the previous hypothesis suggesting that MEN1 patients not harboring mutations in coding regions of the MEN1 gene would carry mutations in non-coding gene regions $(5,8,10,13,18,19,23)$.

Indeed, no previous systematic study investigating both the MEN1 coding and non-coding regions was available, precluding further conclusions (8). Concordantly, reported mutations involving the promoter, $5^{\prime}$ or $3^{\prime}$ untranslated regions are represented by only a few large gross MEN1 deletions not covered by SS and identified by different assays assessing gene copy number $(8,23,28,29,30,56)$. In addition, a single study using SS investigated a minimal promoter region in 23 MEN1-negative MEN1 familial cases and revealed no MEN1 germline mutations (30).

Furthermore, the possible occurrence of a second germline MEN1 pathogenic/likely pathogenic variant in MEN1 cases harboring MEN1 mutations could be ruled out.

\section{Recurrent MEN1 mutations}

We found recurrent MEN1 mutations, which could be due to independent mutational events favoring the existence of warm spot MEN1 mutations in MEN1 $(8,19,23)$. In this line, we previously documented independent mutations in cases 26 and 27 by haplotype analysis (18). Alternatively, recurrent mutations may occur due to founder mutations $(4,28,57,58,59)$. Concordantly, we reported the c.201_201delC (p.A68Pfs*51) founder mutation (case 2, Table 1) in a large MEN1 family with 50 mutation carriers of the southeastern Brazil that came from Veneto, Italy in 1890 (4). However, haplotype analysis could not be 


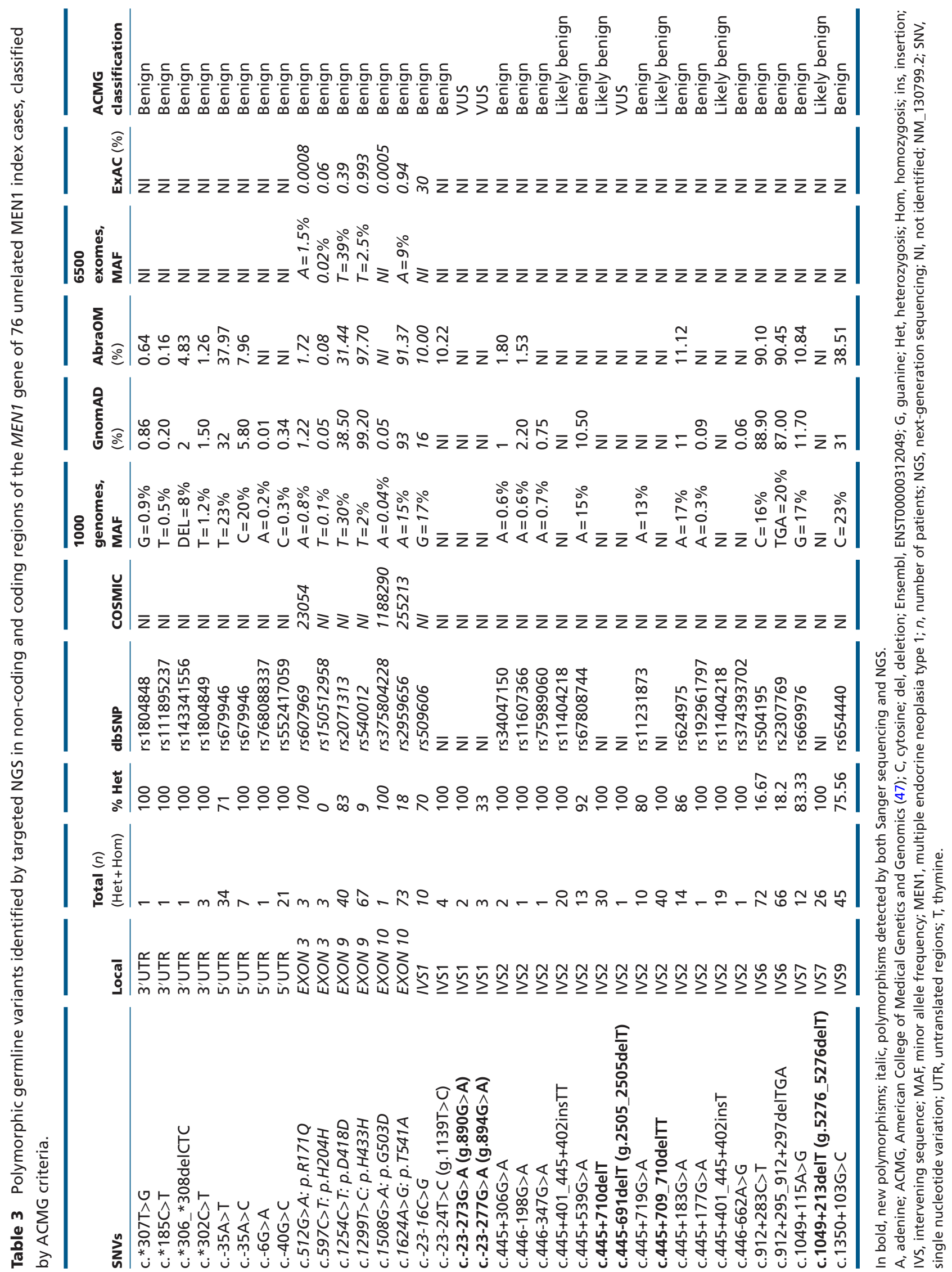


performed in the 22 remaining index cases, preventing adequate distinction between independent and founder mutations. Further careful genealogical, geographic and haplotype studies are planned to clarify this topic.

\section{Pathogenic MEN1 germline variants}

\section{MEN1-tNGS}

As expected, the overall prevalence of germline MEN1 mutations was similar to other studies $(5,19,23,56)$. As anticipated, the prevalence of germline MEN1 mutations was higher in familial than sporadic cases $(5,14)$, and the 16 newly uncovered inherited MEN1 cases lead us to perform genetic screening of their at-risk relatives.

Missense variants represent up to $25 \%$ of the 576 mutations reported in MEN1, whereas in our cases a slightly lesser percentage was observed (14\%) (23). The confirmation of pathogenicity of missense variants is challenging since functional studies of each of them may be infeasible. Most missense and in-frame variants, we found were initially classified as likely pathogenic using the ACMG criteria $(46,47)$. In turn, when we applied equation to calculate probability of at random occurrence of segregation, part of them were reclassified as pathogenic (48). However, the reclassification did not result in changes in the clinical management as no variant was considered benign, likely benign or variant of unknown significance.

\section{MEN1-MLPA assay}

A highly variable frequency of gross MEN1 deletions has been reported (1-33\%) $(5,8,23,28,29,30,56)$. In our series, the prevalence of gross deletions (5\%), considering the different mutation types, was similar to the larger reported series $(<5 \%)$ including MEN1 and MEN1-related phenotypes $(8,23,28,29,30,56)$. In addition, we showed occurrence of gross deletions in $6 \%$ of all familial MEN1 cases and in $37 \%$ of the MEN1-negative familial MEN1 cases, suggesting the importance of the positive familial history as predictive indicator for detection of gross MEN1 deletions. Conversely, no gross deletion was seen in the 11 MEN1-negative sporadic cases. Further in deep studies on MLPA applied to MEN1 are planned.

\section{Likely pathogenic variants}

All in-frame variants were initially classified as likely pathogenic. Concordantly, in-frame variants are likely to cause deleterious effects on menin. One of our cases harbored a variant deleting codons 265-267. Two previous studies reported different in-frame deletions occurring at this same codon in two unrelated MEN1 families $(60,61)$, and a definite segregation was shown in five members of a family (61). The association of typical MEN1 clinical features in our patient, its classification as likely pathogenic by ACMG criteria, and the previously reported mutations in this highly conserved DNA region favor this variant's classification as likely pathogenic. Segregation analysis (SE) may reinforce the pathogenicity of the variant, as observed to missense variants in our study.

\section{Non-pathogenic MEN1 germline variants}

So far, 24 different MEN1 polymorphisms have been reported in more than 1100 MEN1 patients, 12 in the coding region (10 synonymous and 2 nonsynonymous), nine in introns and three in untranslated regions $(8,19)$. The 36 different MEN1 polymorphisms (3 VUS) we identified in the present study represent a substantial increase to those previously detected by SS $(8,19)$. Also, the prevalence of polymorphisms we verified $(36 / 76 ; 47 \%)$ was substantially higher than that reported in the literature $(24 / 1133 ; \sim 2 \% ; P<0.05)(19)$. Comparing our data with those reported by Lemos and Thakker (19), we detected 22 intronic polymorphisms vs nine reported by them (three-fold more), seven occurring in untranslated regions vs three, and 7 exonic polymorphisms vs 12 , respectively. The finding of 4 -fold more polymorphisms detected in non-exonic than in exonic regions clearly reflects the higher ability of tNGS to routinely detect variants in the non-coding region, compared to SS.

Of note, a better characterization of polymorphisms as benign, likely benign or VUS, may be valuable to clearly differentiate them from mutations for at least two reasons. One, variant misclassification may lead to inadequate clinical management and unnecessary surgery interventions (62). In addition, because disease-modifying polymorphisms in genes besides MEN1 could influence MEN1 phenotype $(53,63)$. Overall, our data provide strong evidence that the non-coding region of the MEN1 gene has been scarcely sequenced so far.

The importance of the regional genomic repositories was here reinforced by the absence in six international databases of the polymorphism c.-23-24T $>$ C (g.1139T $>$ C) IVS1, which was present in 10\% of the 609 Brazilian elderly controls from $\mathrm{ABraOM}$ and in our cases. 


\section{Non-mutation carriers}

Compared with 60 mutation carriers, the 16 genuinely non-MEN1 mutation carriers were older at the time of diagnosis, and most patients did not exhibit a third MEN1-related tumor, confirming recent data (14). Of note, five familial non-MEN1 mutation carriers might be phenocopies or harbor so far unreported mutations.

Although one of our focus was to verify the robustness of MEN1-tNGS for the genetic diagnosis of MEN1, we also tested a multi-gene tNGS panel examining CDKNIs (p15, p18, p21, p27) and AIP genes in a limited number of available MEN1-negative carriers. No mutation was detected in CDKNIs and AIP genes, in agreement with the rarity of the association of these genes with MEN1-like phenotypes $(20,21,22)$. Additionally, no gross deletions in $p 27$ and AIP were seen in these cases.

Non-mutation carriers might be due to de novo post-zygotic somatic mutations leading to mosaicism, mutations in so far undiscovered MEN1-related genes or random association of sporadic MEN1-related tumors.

Further studies are needed to clarify whether large multi-gene panels applied to MEN1 in clinical practice would be helpful, accurate and cost-effective. Such panels may not only test MEN1, CDKNIs $(p 15, p 18, p 21, p 27)$ and AIP genes but also HRPT2, CAsR, GNA11, AP2S1 and GCM2 genes, as jaw tumor-HPT syndromes, familial hypocalciuric hypercalcemia and familial isolated HPT may mimic MEN1 phenotypes $(5,8,13,64)$.

Recently, similar custom multi-gene tNGS panels have been applied for several endocrine tumor diseases, as pheochromocytoma/paraganglioma, pituitary adenoma and pancreatic neuroendocrine neoplasia $(41,42,65)$. The effective validation of such panels using tNGS would have the potential to substitute the exhaustive, expensive gene by gene sequential analysis in MEN1negative cases.

At present, WES or WGS have been mostly reserved to patients whose previous genetic analyses to all known MEN1-related genes, and after applying MLPA assay, resulted negative. Beyond WES and WGS, linkage analyses may be applied to informative families either for chromosomal mapping of MEN1 region or to investigate potentially new MEN1-causing genes (8).

Although ACMG classification has not been applied to MEN1 variants, we decided to follow it in an attempt to better characterize DNA variants we found in our patients. Thus, some variants in non-coding region were classified either as likely benign or VUS. This classification may impact clinical practice, as MEN1-negative patients harboring a VUS should not be simply dismissed but clinically followed up periodically.

Potential limitations of the present study could be related to possible tumor mosaicism that could not be investigated in sporadic cases, the relatively limited sample size, and the presence of hypothetical founder mutations in the cases carrying repetitive mutations. However, these pitfalls did not prevent drawing conclusions from our data. Additional functional studies are needed to better characterize the three VUS we found in untranslated, regulatory or deep intronic MEN1 regions by tNGS. Thus, up to now, we cannot convincingly rule out the hypothesis that pathogenic/likely pathogenic variants may occur in MEN1 non-coding region. In cases they occur in patients harboring pathogenic variants, a potential modulating factor could be supported in future.

Our validated protocol based on tNGS long-range PCR showed to be highly effective to be implemented in the clinical practice for MEN1 diagnostic testing, although further confirmatory data involving larger number of patients are welcomed. The decision to analyze other MEN1-related genes (gene panel) in clinical practice should be personalized considering phenotypic features, available methodologies and their regional costeffectiveness.

In summary, we did not find any point or short indel mutations in the non-coding region of the MEN1 in our 76 MEN1 patients, which points to the rareness of such events. In addition, our data support that MEN1 genetic testing based on a tNGS long-range PCR approach is a sensitive, affordable and robust method, with a high diagnostic yield, for detection of MEN1 mutations. This opens the possibility of providing MEN1 testing for a larger number of cases fulfilling the current criteria for MEN1 testing. Ultimately, this potentially promising procedure may expand and improve prenatal and preimplantation genetic diagnosis, genetic screening and counseling, early diagnosis and therapeutic management of MEN1related tumors, which may positively impact morbidity and mortality of patients with MEN1 and MEN1-related phenotypes.

\section{Supplementary data}

This is linked to the online version of the paper at https://doi.org/10.1530/ EJE-18-0430.

\section{Declaration of interest}

The authors declare that there is no conflict of interest that could be perceived as prejudicing the impartiality of this study. 


\section{Funding}

R A C was recipient of a FAPESP fellowship (2013/15388-4). B U received technical training grant (2015/07625-1) from FAPESP and a FAPESP fellowship (2016/07965-0). A A L J received a grant (301871/2016-7) from the National Council for Scientific and Technological Development (CNPq). S P A T is a CAPES (Coordenadoria de Aperfeiçoamento de Pessoal de Nível Superior) National Senior Visiting Professor (PVNS program) at the Federal University of São Paulo, and Senior Professor, University of São Paulo, Brazil. This investigation was supported by CNPq (401990/2010-9) grants to S P A T (Senior Professor - FMUSP) and FAPESP grants to D M L J (2013/19810-2; 2015/25444-4; 2016/07504-2). S J M was supported by Visiting Researcher grant from FAPESP (2015/25444-4). The Large-Scale Sequencing Laboratory (SELA), University of Sao Paulo School of Medicine, was supported by FAPESP grants (2014/50137-5) and MCTI/FINEP/CT-InfraPROINFRA 01/2011 grants (0160/12-sp02). R A Toledo holds a Miguel Servet-I research contract by Institute of Health 'Carlos III' of the Ministry of Economy (CP17/00199) and Competitiveness and is supported by a Fundacíon Olga Torres emerging researcher grant.

\section{References}

1 Brandi ML, Gagel RF, Angeli A, Bilezikian JP, Beck-Peccoz P, Bordi C, Conte-Devolx B, Falchetti A, Gheri RG, Libroia A et al. Guidelines for diagnosis and therapy of MEN type 1 and type 2. Journal of Clinical Endocrinology and Metabolism 200186 5658-5671. (https://doi. org/10.1210/jcem.86.12.8070)

2 Marx SJ. Molecular genetics of multiple endocrine neoplasia types 1 and 2. Nature Reviews Cancer 20055 367-375. (https://doi. org/10.1038/nrc1610)

3 Lourenço DM Jr, Toledo RA, Coutinho FL, Margarido LC, Siqueira AS, dos Santos MA, Montenegro FL, Machado MC \& Toledo SP. The impact of clinical and genetic screenings on the management of the multiple endocrine neoplasia type 1. Clinics 200762 465-476. (https://doi.org/10.1590/S1807-59322007000400014)

4 Lourenço DM Jr, Toledo RA, Mackowiak II, Coutinho FL, Cavalcanti MG, Correia-Deur JE, Montenegro F, Siqueira SA, Margarido LC, Machado MC et al. Multiple endocrine neoplasia type 1 in Brazil. MEN1 founding mutation, clinical features and bone mineral density profile. European Journal of Endocrinology 2008159 259-274. (https://doi.org/10.1530/EJE-08-0153)

5 Thakker RV, Newey PJ, Walls GV, Bilezikian J, Dralle H, Ebeling PR, Melmed S, Sakurai A, Tonelli F, Brandi ML et al. Clinical practice guidelines for multiple endocrine neoplasia type 1 (MEN1). Journal of Clinical Endocrinology and Metabolism 201297 2990-3011. (https:// doi.org/10.1210/jc.2012-1230)

6 Lips CJ, Dreijerink KM, Links TP \& Höppener JW. Recent results of basic and clinical research in MEN1. Opportunities to improve early detection and treatment. Expert Review of Endocrinology and Metabolism 20127 331-344. (https://doi.org/10.1586/eem.12.22)

7 Giraud S, Zhang CX, Serova-Sinilnikova O, Wautot V, Salandre J, Buisson N, Waterlot C, Bauters C, Porchet N, Aubert JP et al. Germline mutation analysis in patients with multiple endocrine neoplasia type 1 and related disorders. American Journal of Human Genetics 1998 63 455-467. (https://doi.org/10.1086/301953)

8 Falchetti A. Genetics of multiple endocrine neoplasia type 1 syndrome: what's new and what's old. F1000Research 2017673. (https://doi.org/10.12688/f1000research.7230.1)

9 Giusti F, Cianferotti L, Boaretto F, Cetani F, Cioppi F, Colao A, Davì MV, Faggiano A, Fanciulli G, Ferolla P et al. Multiple endocrine neoplasia syndrome type 1: institution, management, and data analysis of a nationwide multicenter patient database. Endocrine 2017 58 349-359. (https://doi.org/10.1007/s12020-017-1234-4)

10 Bassett JH, Forbes SA, Pannett AA, Lloyd SE, Christie PT, Wooding C, Harding B, Besser GM, Edwards CR, Monson JP et al. Characterization of mutations in patients with multiple endocrine neoplasia type 1 . American Journal of Human Genetics 199862 232-244. (https://doi. org/10.1086/301729)

11 Vierimaa O, Ebeling TM, Kytölä S, Bloigu S, Eloranta E, Salmi J, Korpi-Hyövälti E, Niskanen L, Orvola A, Elovaara E et al. Multiple endocrine neoplasia type 1 in Northern Finland; clinical features and genotype-phenotype correlation. European Journal of Endocrinology 2007157 285-294. (https://doi.org/10.1530/EJE-07-0195)

12 Goudet P, Murat A, Binquet C, Cardot-Bauters C, Costa A, Ruszniewski P, Niccoli P, Ménégaux F, Chabrier G, Borson-Chazot F et al. Risk factors and causes of death in MEN1 disease. A GTE (Groupe d'Etude des Tumeurs Endocrines) cohort study among 758 patients. World Journal of Surgery 201034 249-255. (https://doi. org/10.1007/s00268-009-0290-1)

13 Marini F, Giusti F, Tonelli F \& Brandi ML. Management impact: effects on quality of life and prognosis in MEN1. Endocrine-Related Cancer 201724 T227-T242. (https://doi.org/10.1530/ERC-17-0203)

14 Laat JM, van der Luijt RB, Pieterman CR, Oostveen MP, Hermus AR, Dekkers OM, de Herder WW, van der Horst-Schrivers AN, Drent ML, Bisschop PH et al. MEN1 redefined, a clinical comparison of mutation-positive and mutation-negative patients. BMC Medicine 201614 182. (https://doi.org/10.1186/s12916-016-0708-1)

15 Agarwal SK, Kester MB, Debelenko LV, Heppner C, EmmertBuck MR, Skarulis MC, Doppman JL, Kim YS, Lubensky IA, Zhuang Z et al. Germline mutations of the MEN1 gene in familial Multiple Endocrine Neoplasia type 1 and related states. Human Molecular Genetics 19976 1169-1175. (https://doi.org/10.1093/hmg/6.7.1169)

16 Chandrasekharappa SC, Guru SC, Manickam P, Olufemi SE, Collins FS, Emmert-Buck FR, Debelenko LV, Zhuang Z, Lubensky EA, Liotta LA et al. Positional cloning of the gene for multiple endocrine neoplasia-type 1. Science 1997276 404-406. (https://doi. org/10.1126/science.276.5311.404)

17 Lemmens I, Van de Ven WJ, Kas K, Zhang CX, Giraud S, Wautot V, Buisson N, De Witte K, Salandre J, Lenoir G et al. Identification of the multiple endocrine neoplasia type 1 (MEN1) gene. The European Consortium on MEN1. Human Molecular Genetics 19976 1177-1183. (https://doi.org/10.1093/hmg/6.7.1177)

18 Toledo RA, Lourenco DM, Coutinho FL, Quedas E, Machowiack I, Machado MC, Montenegro F, Cunha-Neto MB, Liberman B, Pereira MA et al. Novel MEN1 germline mutations in Brazilian families with multiple endocrine neoplasia type 1 . Clinical Endocrinology 200767 377-384. (https://doi.org/10.1111/j.13652265.2007.02895.x)

19 Lemos MC \& Thakker RV. Multiple endocrine neoplasia type 1 (MEN1): analysis of 1336 mutations reported in the first decade following identification of the gene. Human Mutation 200829 22-32. (https://doi.org/10.1002/humu.20605)

20 Pellegata NS, Quintanilla-Martinez L, Siggelkow H, Samsom E, Blink K, Höfler H, Fend F, Graw J \& Atkinson MJ. Germ-line mutations in p27Kip1 cause a multiple endocrine neoplasia syndrome in rats and humans. PNAS 2006103 15558-15563. (https://doi.org/10.1073/pnas.0603877103)

21 Agarwal SK, Mateo CM \& Marx SJ. Rare germline mutations in cyclin-dependent kinase inhibitor genes in multiple endocrine neoplasia type 1 and related states. Journal of Clinical Endocrinology and Metabolism 200994 1826-1834. (https://doi.org/10.1210/ jc.2008-2083)

22 Belar O, De La Hoz C, Pérez-Nanclares G, Castaño L, Gaztambide S \& Spanish MEN1 Group. Novel mutations in MEN1, CDKN1B and AIP genes in patients with multiple endocrine neoplasia type 1 syndrome in Spain. Clinical Endocrinology 201276 719-24. (https:// doi.org/10.1111/j.1365-2265.2011.04269.x)

23 Concolino P, Costella A \& Capoluongo E. Multiple endocrine neoplasia type 1 (MEN1): an update of 208 new germline variants reported in the last nine years. Cancer Genetics 2016209 36-41. (https://doi.org/10.1016/j.cancergen.2015.12.002) 
24 Pieterman CR, Schreinemakers JM, Koppeschaar HP, Vriens MR, Rinkes IH, Zonnenberg BA, van der Luijt RB \& Valk GD. Multiple endocrine neoplasia type 1 (MEN1): its manifestations and effect of genetic screening on clinical outcome. Clinical Endocrinology 200970 575-581. (https://doi.org/10.1111/j.1365-2265.2008.03324.x)

25 Van Leeuwaarde RS, van Nesselrooij BP, Hermus AR, Dekkers OM, de Herder WW, van der Horst-Schrivers AN, Drent ML, Bisschop PH, Havekes B, Vriens MR et al. Impact of delay in diagnosis in outcomes in MEN1. Results from the Dutch MEN1 Study Group. Journal of Clinical Endocrinology and Metabolism 2016101 1159-1165. (https:// doi.org/10.1210/jc.2015-3766)

26 Cuny T, Pertuit M, Sahnoun-Fathallah M, Daly A, Occhi G, Odou MF, Tabarin A, Nunes ML, Delemer B, Rohmer V et al. Genetic analysis in young patients with sporadic pituitary macroadenomas: besides AIP don't forget MEN1 genetic analysis. European Journal of Endocrinology 2013168 533-541. (https://doi.org/10.1530/EJE-12-0763)

27 Toledo SP, Lourenço DM Jr \& Toledo RA. A differential diagnosis of inherited endocrine tumors and their tumor counterparts. Clinics 201368 1039-1056. (https://doi.org/10.6061/clinics/2013(07)24)

28 Tham E, Grandell U, Lindgren E, Toss G, Skogseid B \& Nordenskjöld M. Clinical testing for mutations in the MEN1 gene in Sweden: a report on 200 unrelated cases. Journal of Clinical Endocrinology and Metabolism 200792 3389-3395. (https://doi. org/10.1210/jc.2007-0476)

29 Kong J, Wang O, Nie M, Shi J, Hu Y, Jiang Y, Li M, Xia W, Meng X \& Xing X. Clinical and genetic analysis of multiple endocrine neoplasia Type 1-related primary hyperparathyroidism in Chinese. PLOS ONE 201611 e0166634. (https://doi.org/10.1371/journal.pone.0166634)

30 Owens M, Ellard S \& Vaidya B. Analysis of gross deletions in the MEN1 gene in patients with multiple endocrine neoplasia type 1 . Clinical Endocrinology 200868 350-354. (https://doi.org/10.1111/ j.1365-2265.2007.03045.x)

31 Kamps R, Brandão RD, Bosch BJ, Paulussen AD, Xanthoulea S, Blok MJ \& Romano A. Next-generation sequencing in oncology: genetic diagnosis, risk prediction and cancer classification. International Journal of Molecular Sciences 201718 E308. (https://doi. org/10.3390/ijms18020308)

$32 \mathrm{Ku}$ CS, Cooper DN, Iacopetta B \& Roukos DH. Integrating nextgeneration sequencing into the diagnostic testing of inherited cancer predisposition. Clinical Genetics 201383 2-6. (https://doi. org/10.1111/cge.12028)

33 Korf BR \& Rehm HL. New approaches to molecular diagnosis. JAMA 2013309 1511-1521. (https://doi.org/10.1001/jama.2013.3239)

34 Xuan J, Yu Y, Qing T, Guo L \& Shi L. Next-generation sequencing in the clinic: promises and challenges. Cancer Letters $2013340284-295$. (https://doi.org/10.1016/j.canlet.2012.11.025)

35 Cromer MK, Starker LF, Choi M, Udelsman R, Nelson-Williams C, Lifton RP \& Carling T. Identification of somatic mutations in parathyroid tumors using whole-exome sequencing. Journal of Clinical Endocrinology and Metabolism 201297 E1774-E1781. (https:// doi.org/10.1210/jc.2012-1743)

36 Newey PJ, Nesbit MA, Rimmer AJ, Attar M, Head RT, Christie PT, Gorvin CM, Stechman M, Gregory L, Mihai P et al. Whole-exome sequencing studies of nonhereditary (sporadic) parathyroid adenomas. Journal of Clinical Endocrinology and Metabolism 201297 E1995-E2005. (https://doi.org/10.1210/jc.2012-2303)

37 Li Y, Peng Y, Jiang X, Cheng Y, Zhou W, Su T, Xie J, Zhong X, Song D, $\mathrm{Wu} \mathrm{L}$ et al. Whole exome sequencing of thymic neuroendocrine tumor with ectopic ACTH syndrome. European Journal of Endocrinology 2017176 187-194. (https://doi.org/10.1530/EJE-16-0546)

38 Romero Arenas MA, Fowler RG, San Lucas FA, Shen J, Rich TA, Grubbs EG, Lee JE, Scheet P, Perrier ND \& Zhao H. Preliminary whole-exome sequencing reveals mutations that imply common tumorigenicity pathways in multiple endocrine neoplasia type 1 patients. Surgery 2014156 1351-1357. (https://doi.org/10.1016/j. surg.2014.08.073)
39 Kim BY, Park MH, Woo HM, Jo HY, Kim JH, Choi HJ \& Koo SK. Genetic analysis of parathyroid and pancreatic tumors in a patient with multiple endocrine neoplasia type 1 using whole-exome sequencing. BMC Medical Genetics 201718 106. (https://doi. org/10.1186/s12881-017-0465-9)

40 Isakov O, Rinella ES, Olchovsky D, Shimon I, Ostrer H, Shomrom N \& Friedman E. Missense mutation in the MEN1 gene discovered through whole exome sequencing co-segregates with familial hyperparathyroidism. Genetics Research 201395 114-120. (https:// doi.org/10.1017/S0016672313000141)

41 Backman S, Norlén O, Eriksson B, Skogseid B, Stålberg P \& Crona J. Detection of somatic mutations in gastroenteropancreatic neuroendocrine tumors using targeted deep sequencing. Anticancer Research 201737 705-712. (https://doi.org/10.21873/ anticanres.11367)

42 De Sousa SM, McCabe MJ, Wu K, Roscioli T, Gayevskiy V, Brook K, Rawlings L, Scott HS, Thompson TJ, Earls P et al. Germline variants in familial pituitary tumour syndrome genes are common in young patients and families with additional endocrine tumours. European Journal of Endocrinology 2017176 635-644. (https://doi.org/10.1530/ EJE-16-0944)

43 Marini F, Giusti F \& Brandi ML. Genetic test in multiple endocrine neoplasia type 1 syndrome: an evolving story. World Journal of Experimental Medicine. 20155 124-129. (https://doi.org/10.5493/ wjem.v5.i2.124)

44 Toledo RA \& Dahia PL. Next-generation sequencing for the genetic screening of phaeochromcytomas and paragangliomas: riding the new wave, but with caution. Clinical Endocrinology $20148023-24$ (https://doi.org/10.1111/cen.12357)

45 Crona J, Ljungström V, Welin S, Walz MK, Hellman P \& Björklund P. Bioinformatic challenges in clinical diagnostic application of targeted next generation sequencing: experience from pheochromocytoma. PLOS ONE 201510 e0133210. (https://doi.org/10.1371/journal. pone.0133210)

46 Rehm HL, Bale SJ, Bayrak-Toydemir P, Berg JS, Brown KK, Deignan JL, Friez MJ, Funke BH, Hegde MR, Lyon E et al. ACMG clinical laboratory standards for next-generation sequencing. Genetics in Medicine 201315 733-747. (https://doi.org/10.1038/gim.2013.92)

47 Richards S, Aziz N, Bale S, Bick D, Das S, Gastier-Foster J, Grody WW, Hegde M, Lyon E, Spector E et al. Standards and guidelines for the interpretation of sequence variants: a joint consensus recommendation of the American College of Medical Genetics and Genomics and the Association for Molecular Pathology. Genetics in Medicine 201517 405-424. (https://doi.org/10.1038/gim.2015.30)

48 Jarvik GP \& Browning BL. Consideration of cosegregation in the pathogenicity classification of genomic variants. American Journal of Human Genetics 201698 1077-1081. (https://doi.org/10.1016/j. ajhg.2016.04.003)

49 Lourenço DM Jr, Coutinho FL, Toledo RA, Montenegro FL, CorreiaDeur JE \& Toledo SP. Early-onset, progressive, frequent, extensive, and severe bone mineral and renal complications in multiple endocrine neoplasia type 1-associated primary hyperparathyroidism. Journal of Bone and Mineral Research 201025 2382-2391. (https://doi. org/10.1002/jbmr.125)

50 Coutinho FL, Lourenço DM Jr, Toledo RA, Montenegro FL, CorreiaDeur JE \& Toledo SP. Bone mineral density analysis in patients with primary hyperparathyroidism associated with multiple endocrine neoplasia type 1 after total parathyroidectomy. Clinical Endocrinology 201072 462-468. (https://doi.org/10.1111/j.13652265.2009.03672.x)

51 Gonçalves TD, Toledo RA, Sekiya T, Matuguma SE, Maluf Filho F, Rocha MS, Siqueira SA, Glezer A, Bronstein MD, Pereira MA et al. Penetrance of functioning and nonfunctioning pancreatic neuroendocrine tumors in multiple endocrine neoplasia Type 1 in the second decade of life. Journal of Clinical Endocrinology and Metabolism 201499 E89-E96. (https://doi.org/10.1210/jc.2013-1768) 
52 Toledo RA, Lourenço DM Jr, Liberman B, Cunha-Neto MB, Cavalcanti MG, Moyses CB, Toledo SP \& Dahia PL. Germline mutation in the aryl hydrocarbon receptor interacting protein gene in familial somatotropinoma. Journal of Clinical Endocrinology and Metabolism 200792 1934-1937. (https://doi.org/10.1210/ jc.2006-2394)

53 Longuini VC, Lourenço DM Jr, Sekiya T, Meirelles O, Golcalves TD, Coutinho FL, Francisco G, Osaki LH, Chammas R, Alves VA et al. Association between the p27 RS2066827 variant and tumor multiplicity in patients harboring MEN1 germline mutations. European Journal of Endocrinology 2014171 335-342. (https://doi. org/10.1530/EJE-14-0130)

54 Sekiya T, Bronstein MD, Benfini K, Longuini VC, Jallad RS, Machado MC, Goncalves TD, Osaki LH, Higashi L, Viana-Jr J et al. p27 variant and corticotropinoma susceptibility: a genetic and in vitro study. Endocrine-Related Cancer 201421 395-404. (https://doi. org/10.1530/ERC-13-0486)

55 Agarwal SK, Debelenko LV, Kester MB, Guru SC, Manickam P, Olufemi SE, Skarulis MC, Heppner C, Crabtree JS, Lubensky IA et al. Analysis of recurrent germline mutations in the MEN1 gene encountered in apparently unrelated families. Human Mutation 199812 75-82. (https://doi.org/10.1002/(SICI)10981004(1998)12:2<75::AID-HUMU1>3.0.CO;2-T)

56 Marini F, Giusti F, Fossi C, Cioppi F, Cianferotti L, Masi L, Boaretto F, Zovato S, Cetani F, Colao A et al. Multiple endocrine neoplasia type 1: analysis of germline MEN1 mutations in the Italian multicenter MEN1 patient database. Endocrine 201862 215-233. (https://doi. org/10.1007/s12020-018-1566-8)

57 Olufemi SE, Green JS, Manickam P, Guru SC, Agarwal SK, Kester MB, Dong Q, Burns AL, Spiegel AM, Marx SJ et al. Common ancestral mutation in the MEN1 gene is likely responsible for the prolactinoma variant of MEN1 (MEN1Burin) in four kindreds from Newfoundland. Human Mutation 199811 264-269. (https://doi.org/10.1002/(SICI)1098-1004(1998)11:4<264::AIDHUMU2>3.0.CO;2-V)

58 Burgess JR, Nord B, David R, Greenaway TM, Parameswaran V, Larsson C, Shepherd JJ \& Teh BT. Phenotype and phenocopy: the relationship between genotype and clinical phenotype in a single large family with multiple endocrine neoplasia type 1 (MEN 1). Clinical Endocrinology 200053 205-211. (https://doi.org/10.1046/ j.1365-2265.2000.01032.x)

59 Kytölä S, Villablanca A, Ebeling T, Nord B, Larsson C, Höög A, Wong FK, Välimäki M, Vierimaa O, Teh BT et al. Founder effect in multiple endocrine neoplasia type 1 (MEN 1) in Finland. Journal of Medical Genetics 200138 185-189. (https://doi.org/10.1136/ jmg.38.3.185)

60 Clerici T, Schmid C, Komminoth P, Lange J, Spinas GA \& Brändle M. 10 Swiss kindreds with multiple endocrine neoplasia type 1: assessment of screening methods. Swiss Medical Weekly 2001131 381-386. (https://doi.org/2001/25/smw-09730)

61 Mutch MG, Dilley WG, Sanjurjo F, DeBenedetti MK, Doherty GM, Wells SA Jr, Goodfellow PJ \& Lairmore TC. Germline mutations in the multiple endocrine neoplasia type 1 gene: evidence for frequent splicing defects. Human Mutation 199913 175-185. (https://doi.org/10.1002/(SICI)1098-1004(1999)13:3<175::AIDHUMU1>3.0.CO;2-R)

62 Toledo RA, Hatakana R, Lourenço DM Jr, Lindsey SC, Camacho CP, Almeida M, Lima JV Jr, Sekiya T, Garralda E, Naslavsky MS et al. Comprehensive assessment of the disputed RET Y791F variant shows no association with medullary thyroid carcinoma susceptibility. Endocrine-Related Cancer 201522 65-76. (https://doi.org/10.1530/ ERC-14-0491)

63 Peculis R, Balcere I, Rovite V, Megnis K, Valtere A, Stukens J, Arnicane L, Nikitina-Zake L, Lejnieks A, Pirags V et al. Polymorphisms in MEN1 and DRD2 genes are associated with the occurrence and characteristics of pituitary adenomas. European
Journal of Endocrinology 2016175 145-153. (https://doi.org/10.1530/ EJE-15-0879)

64 Guan B, Welch JM, Sapp JC, Ling H, Li Y, Johnston JJ, Kebebew E, Biesecker LG, Simonds WF, Marx SJ et al. GCM2-activating mutations in familial isolated hyperparathyroidism. American Journal of Human Genetics 201699 1034-1044. (https://doi.org/10.1016/j. ajhg.2016.08.018)

65 Toledo RA, Burnichon N, Cascon A, Benn DE, Bayley JP, Welander J, Tops CM, Firth H, Dwight T et al. Consensus Statement on nextgeneration-sequencing-based diagnostic testing of hereditary phaeochromocytomas and paragangliomas. Nature Reviews Endocrinology 201713 233-247. (https://doi.org/10.1038/ nrendo.2016.185)

66 Ellard S Hattersley AT Brewer CM Vaidya B. Detection of an MEN1 gene mutation depends on clinical features and supports current referral criteria for diagnostic molecular genetic testing. Clinical Endocrinology 200562 169-175. (https://doi.org/10.1111/j.13652265.2005.02190.x)

67 Cebrián A Ruiz-Llorente S Cascón A Pollán M Díez JJ Picó A Tellería D Benítez J Robledo M. Mutational and gross deletion study of the MEN1 gene and correlation with clinical features in Spanish patients. Journal of Medical Genetics $2003 \mathbf{4 0}$ e72.

68 Klein RD Salih S Bessoni J Bale AE. Clinical testing for multiple endocrine neoplasia type 1 in DNA diagnostic laboratory. Genetics in Medicine 20057 131-138.

69 Ozturk M Chiu CY Akdeniz N Jenq SF Chang SC Hsa CY Jap TS. Two novel mutations in the MEN1 gene in subjects with multiple endocrine neoplasia-1. Journal of Endocrinological Investigation 2006 29 523-527.

70 Bergman L Teh B Cardinal J Palmer J Walters M Shepherd J Cameron D Hayward N. Identification of MEN1 gene mutations in families with MEN 1 and related disorders. British Journal of Cancer 200083 1009-1014. (https://doi.org/10.1054/ bjoc.2000.1380)

71 Wautot V Vercherat C Lespinasse J Chambe B Lenoir GM Zhang CX Porchet N Cordier M Béroud C Calender A. Germline mutation profile of MEN1 in multiple endocrine neoplasia type 1: search for correlation between phenotype and the functional domains of the MEN1 protein. Human Mutation 200220 35-47. (https://doi. org/10.1002/humu.10092)

72 Teh BT Kytölä S Farnebo F Bergman L Wong FK Weber G Hayward N Larsson C Skogseid B Beckers A Phelan C Edwards M Epstein M Alford F Hurley D Grimmond S Silins G Walters M Stewart C Cardinal J Khodaei S Parente F Tranebjaerg L Jorde R Salmela P et al. Mutation analysis of the MEN1 gene in multiple endocrine neoplasia type 1 , familial acromegaly and familial isolated hyperparathyroidism. Journal of Clinical Endocrinology \& Metabolism 199883 2621-2626. (https://doi.org/10.1210/jc.83.8.2621)

73 Morelli A Falchetti A Martineti V Becherini L Mark M Friedman E Brandi ML. MEN1 gene mutation analysis in Italian patients with multiple endocrine neoplasia type 1. European Journal of Endocrinology 2000142 131-137.

74 Görtz B, Roth J, Krähenmann A, de Krijger RR, Muletta-Feurer S, Rütimann K, Saremaslani P, Speel EJ, Heitz PU, Komminoth P. Mutations and Allelic Deletions of the MEN1 Gene Are Associated with a Subset of Sporadic Endocrine Pancreatic and Neuroendocrine Tumors and Not Restricted to Foregut Neoplasms. American Journal of Pathology 1999154 429-436.

75 Martín-Campos JM, Catasús L, Chico A, Mayoral C, Lagarda E, Gallart L, Mato E, Rodríguez-Espinosa J, Matías-Guiu X, De Leiva A, Blanco-Vaca F. Molecular pathology of multiple endocrine neoplasia type I: two novel germline mutations and updated classification of mutations affecting MEN1 gene. Diagnostic Molecular Pathology 1999 8 195-204.

76 Asteria C, Faglia G, Roncoroni R, Borretta G, Ribotto P, Beck-Peccoz P. Identification of three novel menin mutations (c.741delGTCA, 
c.1348T>C, c.1785delA) in unrelated Italian families affected with multiple endocrine neoplasia type 1: Additional information for mutational screening. Human Mutation 200117237.

77 Heppner C, Kester MB, Agarwal SK, Debelenko LV, Emmert-Buck MR, Guru SC, Manickam P, Olufemi SE, Skarulis MC, Doppman JL,

Alexander RH, Kim YS, Saggar SK, Lubensky IA, Zhuang Z, Liotta LA, Chandrasekharappa SC, Collins FS, Spiegel AM, Burns AL, Marx SJ.
Somatic mutation of the MEN1 gene in parathyroid tumours. Nature Genetics 199716 375-378.

78 Warner J, Epstein M, Sweet A, Singh D, Burgess J, Stranks S, Hill P, Perry-Keene D, Learoyd D, Robinson B, Birdsey P, Mackenzie E, Teh BT, Prins JB, Cardinal J. Genetic testing in familial isolated hyperparathyroidism: unexpected results and their implications. Journal of Medical Genetics 200441 155-160.

Received 19 May 2018

Revised version received 8 September 2018

Accepted 24 September 2018 